\title{
BMJ Open Occupational variation in incidence of bladder cancer: a comparison of population-representative cohorts from Nordic countries and Canada
}

\author{
Kishor Hadkhale, ${ }^{1}$ Jill MacLeod, ${ }^{2}$ Paul A Demers, ${ }^{2,3,4}$ Jan Ivar Martinsen, ${ }^{5}$ \\ Elisabete Weiderpass, ${ }^{5,6,7,8}$ Kristina Kjaerheim, ${ }^{5}$ Elsebeth Lynge, ${ }^{9}$ Pär Sparen, ${ }^{8}$ \\ Laufey Tryggvadottir, ${ }^{10,11}$ M Anne Harris, ${ }^{2,3,12}$ Michael Tjepkema, ${ }^{13}$ Paul A Peters, ${ }^{14}$ \\ Eero Pukkala ${ }^{1,15}$
}

To cite: Hadkhale K, MacLeod J, Demers PA, et al. Occupational variation in incidence of bladder cancer: a comparison of population-representative cohorts from Nordic countries and Canada. BMJ Open 2017;7:e016538. doi:10.1136/ bmjopen-2017-016538

- Prepublication history for this paper is available online. To view these files please visit the journal online (http://dx.doi. org/10.1136/bmjopen-2017016538).

Received 21 February 2017 Revised 2 June 2017 Accepted 12 June 2017

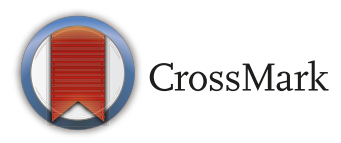

For numbered affiliations see end of article.

Correspondence to Dr Kishor Hadkhale; kishor.hadkhale@staff.uta.fi

\section{ABSTRACT}

Objectives The objective of this study was to compare occupational variation of the risk of bladder cancer in the Nordic countries and Canada.

Methods In the Nordic Occupational Cancer study (NOCCA), 73653 bladder cancer cases were observed during follow-up of 141.6 million person-years. In the Canadian Census Health and Environment Cohort (CanCHEC), 8170 cases were observed during the followup of 36.7 million person-years. Standardised incidence ratios with $95 \% \mathrm{Cl}$ were estimated for 53 occupations in the NOCCA cohort and HR with $95 \%$ Cls were estimated for 42 occupations in the CanCHEC.

Results Elevated risks of bladder cancer were observed among hairdressers, printers, sales workers, plumbers, painters, miners and laundry workers. Teachers and agricultural workers had reduced risk of bladder cancer in both cohorts. Chimney-sweeps, tobacco workers and waiters had about 1.5-fold risk in the Nordic countries; no risk estimates for these categories were given from the CanCHEC cohort.

Conclusion We observed different occupational patterns in risk of bladder cancer in Nordic countries and Canada. The only occupation with similarly increased risk was observed among sales workers. Differences in smoking across occupational groups may explain some, but not all, of this variation.

\section{INTRODUCTION}

Bladder cancer is the ninth most common cancer in the world and occupation has been identified as the most important risk factor second to smoking. ${ }^{1}$ It has been estimated that occupational exposure could account for as much as $20 \%$ of all bladder cancers diagnosed in industrialised countries. ${ }^{12}$ In the Nordic countries, bladder cancer is the fifth most common cancer in men and 15th most common cancer in women. ${ }^{3}$ Age-standardised incidence rates for bladder cancer increased until 1990, with the highest incidence in

\section{Strengths and limitations of this study}

- Only few countries have directly linked information on cancer and census data and this study provides in-depth analysis with high statistical power of population-level comparison using linkage data in Nordic countries and Canada.

- The availability of these two large cohorts and long duration of follow-up conducted in different areas of the world provided an opportunity to examine occupational variation of bladder cancer risk in different geographic regions.

- The lack of data on smoking information and workplace exposure to chemical solvents in this study would better explain the risk associated with bladder cancer.

Denmark and lowest in Finland. ${ }^{4}$ In Canada, bladder cancer is the fourth most common cancer in men and 12th most common cancer in women. There has been little to no change in bladder cancer incidence among both male and female Canadians in the last decade. $^{5}$

Associations with bladder cancer have been observed for $>40$ occupations. While some findings have been consistent, others have been inconsistent or limited. ${ }^{67}$ In-depth studies with high statistical power are required to establish clear associations of occupational risks of bladder cancer. ${ }^{8}$ Furthermore, occupational bladder cancer risk factors may have changed over time, suggesting a need for more current evidence. $^{10}$ Outside of the Nordic countries, only few countries have directly linked information on cancer and census data. The availability of these two cohorts conducted in different areas of the world provided 


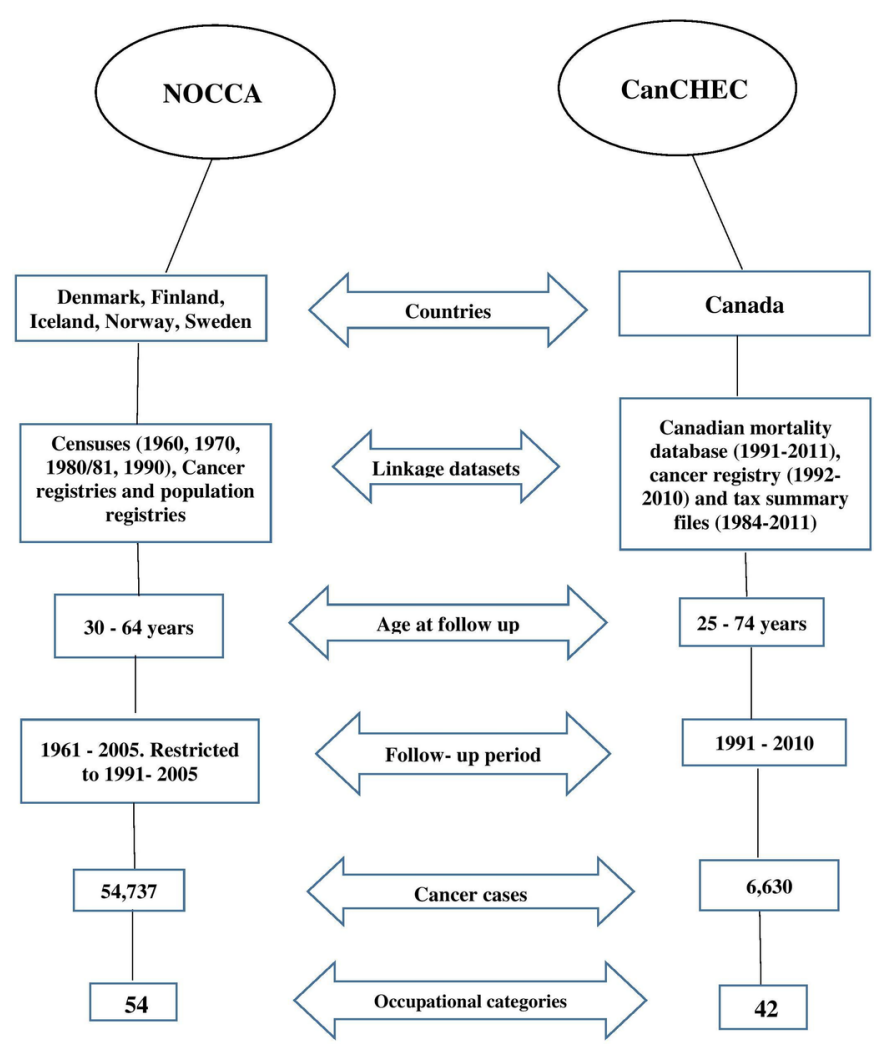

Figure 1 Flowchart of the methodological procedure in NOCCA cohort and CanCHECs. CanCHEC, the Canadian Census Health and Environment Cohort; NOCCA, the Nordic Occupational Cancer study.

an opportunity to examine occupational variation of bladder cancer risk in Nordic and Canadian population-based cohorts.

\section{MATERIALS AND METHODS}

The present study is based on the cohort derived from the Nordic Occupational Cancer study (NOCCA) followed up from 1961 to 2005 and the Canadian Census Health and Environment Cohort (CanCHEC) followed up from 1991 to 2005 derived from the Canadian Census Mortality and Cancer Follow-up Study (figure 1).

The NOCCA cohort comprises individuals in Denmark, Finland, Iceland, Norway and Sweden who participated in one or more population censuses in 1960, 1970, 19801981 or 1990, who were between the ages of 30 and 64 years and living in the country on 1 January after the census. The present study used the data from the cohort followed up only from the period 1991 to 2005 to increase comparability with the CanCHEC study. The census records include questionnaire-based information on economic activity, occupation and industry, which were centrally coded and computerised in the national statistics offices. Occupations were coded into $>300$ categories according to the national adaptations of the International Standard Classification of Occupations (ISCO) from 1958 in Finland, Norway and Sweden. In Denmark, special national nomenclature was used with a distinction from self-employed persons, family workers, salaried employees, skilled workers and unskilled workers. In Iceland, it was coded according to the ISCO-68 classification and later converted into ISCO-58 with instructions from International Labour Organisation. For the NOCCA study, the original national codes were converted according to the Nordic occupational classification (NYK) into 53 categories with 1 additional category of economically inactive persons. NYK is the Nordic adaptation of ISCO from 1958 (details of the occupational categories in NOCCA study are available at: http://astra.cancer.fi/NOCCA/categories.html).

Data on incident cancer cases were obtained from the national cancer registries in each of the Nordic countries. These registries capture information from clinical and pathological departments, general practitioners, private clinics and death registers that are fairly similar in all Nordic countries. ${ }^{11}$ All the patients had bladder cancer at the age of diagnosis. Details of the NOCCA study have been described elsewhere. ${ }^{12}$ NOCCA results are presented in standardised incidence ratios (SIRs) to estimate risks of bladder cancer across occupational groups with rates for the entire national study populations used as the reference rates. The SIR was calculated as the ratio of observed to expected cases. Exact $95 \%$ CIs were defined based on a Poisson distribution.

The CanCHEC cohort was derived from respondents to the 1991 Canadian Census who were included in the Canadian Census Mortality and Follow-Up Study. ${ }^{13}$ The present study used data from the linkage of the 1991 Canadian Census 2B (long form) with the Canadian Mortality Database (1991-2011), Canadian Cancer Registry (19922010) and Historical Tax Summary Files (1984-2011). The nationally representative cohort included 2735152 individuals of the Canadian non-institutional resident population aged from 25 to 74 years on the census day (4 June 1991), who were residents of Canada and among the $20 \%$ of Canadian household selected to complete the long-form census questionnaire. Occupation, coded according to the 1991 Standard Occupational Classification (SOC-91), and socioeconomic characteristics were obtained from the census. The majority of the occupation groupings were comparable between CanCHEC and NOCCA. However, some groups such as chimney-sweeps appeared only in NOCCA while others, such as waiters, were contained within a broader occupational group of food and beverage workers and tobacco workers in a broader group of food processing workers. The CanCHEC was followed up for cancer morbidity through linkage to the Canadian Cancer Registry database through deterministic and probabilistic methods.

Person-time at risk was counted from the cohort entry on 4 June 1991 to date of disease diagnosis, death and loss to follow-up or end of follow-up on 31 December 2010, whichever occurred first. For the purpose of analyses, the first incident primary bladder cancer was considered and groups were re-coded based on the four-digit SOC codes. Details of the CanCHEC study have been 

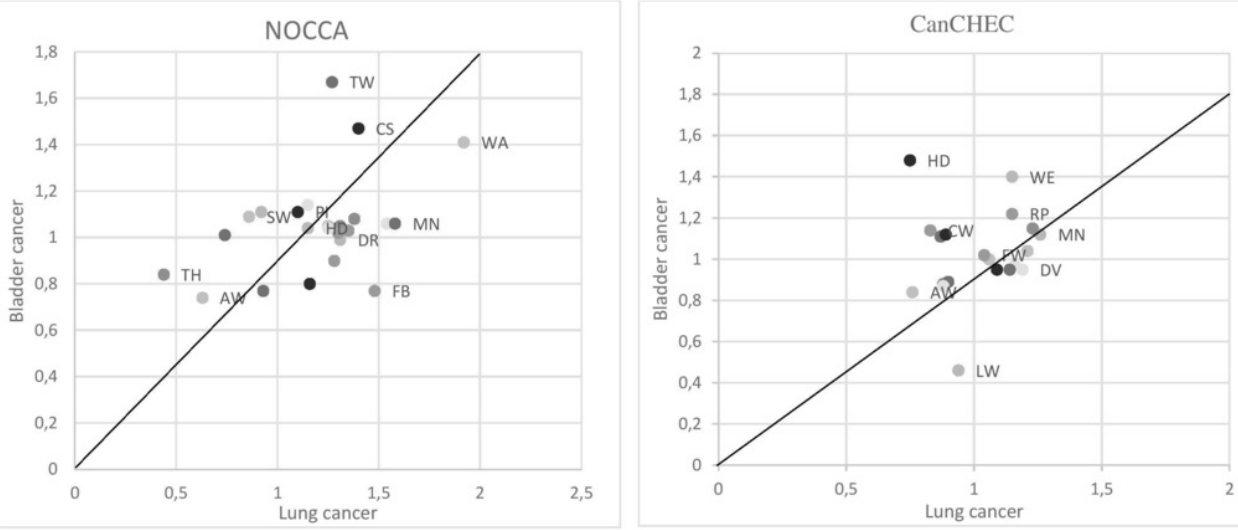

Figure 2 Correlation of bladder and lung cancer in men in NOCCA cohort and CanCHEC. AM, administrators and managers; AW, agriculture workers; CanCHEC, Canadian Census Health and Environment Cohort; $\mathrm{CH}$, chemical workers; CS, chimneysweeps; CW, construction workers; DV, drivers; EW, electrical workers; FB, food and beverage workers; FF, fire fighters; FP, food-processing workers; FW, forestry workers; HD, hairdressers; LW, laundry workers; MN, miners; MW, metal workers; NOCCA; Nordic Occupational Cancer study; PA, painters; PI, printers; PL, plumbers; RP, rubber and plastics workers; SIR, standardised incidence ratio; SW, sales workers; TH, teachers; TW, tobacco workers; WA, waiters; WE, welders.

described elsewhere. ${ }^{13}$ Cox proportional HRs and 95\% CIs were calculated using Cox proportional hazards disease-free survival analysis to estimate risks of bladder cancer associated with employment according to occupation at baseline. In the absence of information regarding potential confounders such as lifestyle factors, including smoking, physical activity and diet, models were adjusted for age group, region and level of education. In accordance with Statistics Canada disclosure guidelines, no counts $<5$ or corresponding model outputs are reported, and all person-years and counts are randomly rounded to base 5. Results may also be suppressed where counts $<5$ would be identified due to additivity across subgroups. STROBE guidelines was followed to report each sections, where applicable.

Demographic information and risk of bladder cancer by occupational category are presented by sex for the NOCCA cohort and the CanCHEC. Due to the absence of information on individual smoking behaviour, we also examined the risk of lung cancer and its relationship with the risk of bladder cancer in men across occupational groups (figure 2).

\section{ETHICAL CONSIDERATIONS}

Ethical committees and data inspection boards from each Nordic country approved the NOCCA study. The CanCHEC study was approved by the University of Toronto Health Sciences Research Ethics Board.

\section{RESULTS}

In the NOCCA cohort, 73653 cases of bladder cancer were diagnosed among 14902573 (50.0\% men) individuals over the 1991-2005 follow-up period (141.6 million person-years) (table 1). In the CanCHEC, 8170 cases of bladder cancer were diagnosed among 2051315 (54.0\% men) individuals during the 1991-2010 follow-up period (36.7 million person-years).

The greatest statistically significant excess risks of bladder cancer for male workers in the NOCCA cohort were observed among tobacco workers (1.67), chimney-sweeps (1.47) and waiters (1.41), occupations that were not examined in CanCHEC (table 2). Lower but statistically significant elevated risks in NOCCA were also observed among sales workers, printers, metal workers and painters. Among them, only sales workers showed an elevated HR in CanCHEC. In turn, there were increased risks in the CanCHEC among hairdressers, welders and administrators and managers, while the SIRs for these occupations were close to 1.0 except for hairdressers in the NOCCA study (table 2). The correlation coefficient (r) of lung and bladder cancer in men in NOCCA and CanCHEC study was observed as 0.75 and 0.81 , respectively (figure 2).

The greatest statistically significant excess risks for female workers in the NOCCA cohort were observed among tobacco workers (1.65), occupation that was not examined separately in CanCHEC (table 3). Statistically significant excess risk in CanCHEC was observed only among plumbers. Statistically significant elevated risks in NOCCA were also observed among printers, chemical workers, hairdressers, waiters, sales workers and administrative managers. While in CanCHEC, an insignificant increased risk was observed among printers, hairdresser and sales workers. Waiters were not examined separately in the CanCHEC study (table 3). Reduced risks were consistently observed for teachers and agriculture workers in both cohorts.

\section{DISCUSSION}

This comparison of results from two large cohort studies revealed occupational variation in bladder cancer risks. 
Table 1 Demographic and other variables of the study population in Nordic countries (NOCCA) and Canada (CanCHEC) cohorts

\begin{tabular}{|c|c|c|c|c|}
\hline \multirow[b]{2}{*}{ Variable } & \multicolumn{2}{|l|}{ NOCCA } & \multicolumn{2}{|l|}{ CanCHEC } \\
\hline & Category & Number (\%) & Category & Number (\%) \\
\hline $\begin{array}{l}\text { Population by country/ } \\
\text { province } \\
\text { NOCCA (1961-2005) } \\
\text { CanCHEC (1991-2010) }\end{array}$ & $\begin{array}{l}\text { Denmark } \\
\text { Finland } \\
\text { Iceland } \\
\text { Norway } \\
\text { Sweden }\end{array}$ & $\begin{array}{l}2013346(13.5 \%) \\
3404800(22.8 \%) \\
120995(0.8 \%) \\
2562674(17.2 \%) \\
6800758(45.6 \%)\end{array}$ & $\begin{array}{l}\text { Atlantic } \\
\text { Quebec } \\
\text { Ontario } \\
\text { Manitoba } \\
\text { Saskatchewan } \\
\text { Alberta } \\
\text { British Columbia } \\
\text { Yukon, NW Territory and } \\
\text { Nunavut }\end{array}$ & $\begin{array}{l}162135(7.9 \%) \\
502495(24.5 \%) \\
756295(36.8 \%) \\
87565(4.3 \%) \\
77855(3.8 \%) \\
200135(9.7 \%) \\
243735(11.8 \%) \\
21100(1.2 \%)\end{array}$ \\
\hline Population by sex & $\begin{array}{l}\text { Male } \\
\text { Female }\end{array}$ & $\begin{array}{l}7447726(49.97 \%) \\
7454847(50.03 \%)\end{array}$ & $\begin{array}{l}1108410(54.03 \%) \\
942905(45.96 \%)\end{array}$ & \\
\hline $\begin{array}{l}\text { Bladder cancer cases } \\
\text { by country/province } \\
\text { NOCCA (1991-2005) } \\
\text { CanCHEC (1991-2010) }\end{array}$ & $\begin{array}{l}\text { Denmark } \\
\text { Finland } \\
\text { Iceland } \\
\text { Norway } \\
\text { Sweden }\end{array}$ & $\begin{array}{l}17525(23.79 \%) \\
11109(15.08 \%) \\
573(0.78 \%) \\
13798(18.73 \%) \\
30648(41.61 \%)\end{array}$ & $\begin{array}{l}\text { Atlantic } \\
\text { Quebec } \\
\text { Ontario } \\
\text { Manitoba } \\
\text { Saskatchewan } \\
\text { Alberta } \\
\text { British Columbia } \\
\text { Yukon, NW territory and } \\
\text { Nunavut }\end{array}$ & $\begin{array}{l}686(8.4 \%) \\
2356(28.8 \%) \\
2436(29.8 \%) \\
350(4.3 \%) \\
383(4.7 \%) \\
839(10.3 \%) \\
1082(13.2 \%) \\
42(0.5 \%)\end{array}$ \\
\hline $\begin{array}{l}\text { Bladder cancer cases } \\
\text { by age group (years) }\end{array}$ & $\begin{array}{l}30-34 \\
35-44 \\
45-54 \\
55-64 \\
65-74 \\
75+\end{array}$ & $\begin{array}{l}15(0.02 \%) \\
506(0.69 \%) \\
3546(4.82 \%) \\
12241(16.62 \%) \\
25258(34.29 \%) \\
32087(43.56 \%)\end{array}$ & $\begin{array}{l}25-34 \\
35-44 \\
45-54 \\
55-64 \\
65-74\end{array}$ & $\begin{array}{l}396(4.8 \%) \\
1365(16.7 \%) \\
2558(31.3 \%) \\
2972(36.4) \\
879(10.7 \%)\end{array}$ \\
\hline
\end{tabular}

CanCHEC, Canadian Census Health and Environment Cohort; NOCCA, Nordic Occupational Cancer study.

Generally, the excesses in a given occupation seen in one cohort were not seen in the other. Male hairdressers in CanCHEC and female hairdressers in NOCCA showed a marked excess risk of bladder cancer while there was almost no indication of an excess risk among female hairdressers in CanCHEC and non-significant increased risk among male hairdressers in NOCCA. The finding of an excess risk is consistent with two different meta-analyses: (1) Harling and colleagues ${ }^{14}$ reposted a summary risk ratio (SRR) of 1.70 (95\% CI 1.10 to 2.88) and (2) Takkouche and colleagues, ${ }^{15}$ a risk ratio (RR) of $1.30(95 \%$ CI 1.20 to 1.42). Hairdressers are exposed to chemical compounds of aromatic amines such as benzidine, toluidine and aromatic nitrous compounds, and exposure to these chemical compounds has been linked to an increased risk of bladder cancer. ${ }^{16}$ In particular, long-term exposure ( $\geq 10$ years) as a hairdresser has been associated with greater risk of bladder cancer. ${ }^{14} 17$

Exposures to carcinogenic chemicals among hairdressers appear to have been diminishing in recent decades. ${ }^{18}$ Following the ban on use of aromatic amines in the European Union in 1980s, thereafter a similar ban was also imposed in Canada. Some more recent studies that examined exposures after these bans have not reported excess risks of bladder cancer, but some studies have reported that banned substances are still in use, leading to the potential for ongoing exposure. ${ }^{19}$ The period-specific stratified analysis of the NOCCA study from 1991 to 2005 also shows a similar decrease in risk among hairdressers over time in the Nordic countries and in Canada (results not shown). As our cohorts represent the follow-up from 1991, the highest risks observed in 1990s may have been due to the use of aromatic amines in dye products, which are not used any more. ${ }^{19}$

We observed some evidence of an association between bladder cancer and employment as a printer in this comparative study, with the greatest excess risk observed among Nordic women. A meta-analysis of case-control studies from six European countries observed that occupation related to printing had an up to $80 \%$ greater risk of bladder cancer than the general population (OR 1.81, $95 \%$ CI 1.03 to 3.17$).{ }^{20}$ A Spanish study also observed a significantly elevated risk of bladder cancer among men in printing industry (OR 5.4, 95\% CI 1.62 to 17.72$){ }^{21}$ Printers are mainly exposed to printing inks consisting of pigments and a solvent. ${ }^{22}$ Exposures to chemical agents 
Table 2 Bladder cancer risk in men by occupation in NOCCA and CanCHEC

\begin{tabular}{|c|c|c|c|c|c|c|}
\hline \multirow[b]{2}{*}{ Occupational category } & \multicolumn{3}{|c|}{ NOCCA $(n=54737)$} & \multicolumn{3}{|c|}{ CanCHEC $^{*}(n=6630)$} \\
\hline & Cases & SIR & $95 \% \mathrm{Cl}$ & Cases & HR & $95 \% \mathrm{Cl}$ \\
\hline AM & 2704 & 1.01 & 0.98 to 1.05 & 1115 & 1.11 & 1.04 to 1.19 \\
\hline AW & 4356 & 0.74 & 0.72 to 0.77 & 455 & 0.84 & 0.76 to 0.93 \\
\hline $\mathrm{CH}$ & 514 & 0.90 & 0.81 to 0.97 & 45 & 1.14 & 0.84 to 1.54 \\
\hline CS & 53 & 1.47 & 1.10 to 1.92 & & & \\
\hline $\mathrm{CW}$ & 1704 & 1.06 & 1.01 to 1.10 & 410 & 0.95 & 0.86 to 1.06 \\
\hline DV & 2899 & 0.99 & 0.95 to 1.03 & 520 & 0.95 & 0.87 to 1.04 \\
\hline EW & 1519 & 1.05 & 1.00 to 1.11 & 150 & 0.88 & 0.75 to 1.04 \\
\hline $\mathrm{FF}$ & 581 & 0.77 & 0.71 to 0.83 & 25 & 0.89 & 0.60 to 1.33 \\
\hline FB & 64 & 1.09 & 0.84 to 1.39 & 160 & 1.00 & 0.85 to 1.17 \\
\hline FP & 683 & 0.77 & 0.72 to 0.83 & 60 & 0.77 & 0.59 to 1.01 \\
\hline FW & 762 & 0.80 & 0.75 to 0.86 & 85 & 1.02 & 0.82 to 1.27 \\
\hline $\mathrm{HD}$ & 140 & 1.14 & 0.96 to 1.35 & 25 & 1.48 & 1.01 to 2.19 \\
\hline LW & 80 & 1.04 & 0.82 to 1.29 & 5 & 0.46 & 0.22 to 0.97 \\
\hline MW & 901 & 1.08 & 1.01 to 1.16 & 230 & 0.97 & 0.85 to 1.10 \\
\hline $\mathrm{MN}$ & 246 & 1.06 & 0.93 to 1.20 & 60 & 1.12 & 0.87 to 1.45 \\
\hline PA & 753 & 1.05 & 1.01 to 1.12 & 50 & 1.15 & 0.86 to 1.54 \\
\hline $\mathrm{PL}$ & 469 & 1.02 & 0.93 to 1.12 & 90 & 0.95 & 0.77 to 1.16 \\
\hline $\mathrm{PI}$ & 502 & 1.11 & 1.02 to 1.21 & 40 & 1.04 & 0.77 to 1.41 \\
\hline $\mathrm{RP}$ & 713 & 1.04 & 0.97 to 1.12 & 30 & 1.22 & 0.84 to 1.78 \\
\hline SW & 2514 & 1.11 & 1.07 to 1.15 & 525 & 1.12 & 1.02 to 1.22 \\
\hline $\mathrm{TH}$ & 1372 & 0.84 & 0.80 to 0.90 & 230 & 0.87 & 0.76 to 1.00 \\
\hline TW & 17 & 1.67 & 1.02 to 2.67 & & & \\
\hline WA & 122 & 1.41 & 1.17 to 1.68 & & & \\
\hline WE & 484 & 1.03 & 0.94 to 1.12 & 100 & 1.40 & 1.15 to 1.70 \\
\hline
\end{tabular}

Empty box indicates no information available. Bold indicates statistically significant inceased risk. Italics indicates statistically significant decreased risk.

${ }^{*}$ Model adjusted for age, sex, region and level of education.

$\mathrm{AM}$, administrators and managers; AW, agriculture workers; CanCHEC, Canadian Census Health and Environment Cohort; $\mathrm{CH}$, chemical workers; CS, chimney-sweeps; CW, construction workers; DV, drivers; EW, electrical workers; FB, food and beverage workers; FF, fire fighters; FP, food-processing workers; FW, forestry workers; HD, hairdressers; LW, laundry workers; MN, miners; MW, metal workers; NOCCA; Nordic Occupational Cancer study; PA, painters; PI, printers; PL, plumbers; RP, rubber and plastics workers; SIR, standardised incidence ratio; SW, sales workers; TH, teachers; TW, tobacco workers; WA, waiters; WE, welders.

in the printing industry have been associated with an increased risk of bladder cancer. ${ }^{21}$

Small yet consistent excess risks of bladder cancer were observed for sales workers of both sexes in the Canadian and Nordic cohorts. This association has been observed previously for men in a Swedish cohort study. ${ }^{10}$ In the Swedish study, physical inactivity and sedentary work were suggested as the probable cause of increased risk of bladder cancer. The findings in this Swedish study and the present study are not independent due to marked overlap in the data between these studies. The meta-analysis by 't Mannetje and Pearce ${ }^{23}$ reported a smoking-adjusted excess risk of bladder cancer among female sales workers. The study observed positive causal association with duration of employment among sales workers. Lower frequency of urination and reduced fluid intake were plausible explanations for the risk of bladder cancer in this group. ${ }^{23}$

Elevated risk of bladder cancer was observed among female, but not male, drivers in our comparative study. A meta-analysis of the occupational risk of bladder cancer study observed a significantly increased risk of bladder cancer among bus drivers with SRR of 1.29 (95\% CI 1.08 to 1.53$){ }^{8}$ Similarly, a significant positive dose-response relationship between the duration of employment as a truck driver and the risk of bladder cancer was observed in a study by Silverman and colleagues. ${ }^{7}$ This excess risk may be attributable to exposure to several air pollutants such as polycyclic aromatic hydrocarbons (PAH) and diesel engine exhausts, which may interact with the urothelium of the bladder. ${ }^{7}$ However, a case-control study from the USA examined the lifetime occupational history of 
Table 3 Bladder cancer risk in women by occupation in the NOCCA and CanCHEC

\begin{tabular}{|c|c|c|c|c|c|c|}
\hline \multirow[b]{2}{*}{ Occupational categories } & \multicolumn{3}{|c|}{ NOCCA $(n=18916)$} & \multicolumn{3}{|c|}{ CanCHEC* $^{*}(n=1540)$} \\
\hline & Cases & SIR & $95 \% \mathrm{Cl}$ & Cases & HR & $95 \% \mathrm{Cl}$ \\
\hline AM & 137 & 1.17 & 1.00 to 1.40 & 110 & 0.93 & 0.77 to 1.13 \\
\hline AW & 342 & 0.70 & 0.60 to 0.74 & 50 & 0.88 & 0.66 to 1.18 \\
\hline $\mathrm{CH}$ & 63 & 1.45 & 1.11 to 1.86 & $<5$ & - & - \\
\hline CS & 0 & - & 0.00 to 52.7 & & & \\
\hline CW & 11 & 1.00 & 0.50 to 1.80 & 10 & 1.25 & 0.63 to 2.51 \\
\hline DV & 41 & 1.24 & 0.90 to 1.70 & 10 & 1.09 & 0.64 to 1.85 \\
\hline EW & 72 & 1.00 & 0.79 to 1.26 & 5 & 0.65 & 0.27 to 1.57 \\
\hline FF & 14 & 1.08 & 0.58 to 1.80 & $<5$ & - & - \\
\hline FB & 12 & 1.07 & 0.55 to 1.87 & 125 & 1.07 & 0.89 to 1.29 \\
\hline FP & 212 & 1.02 & 0.88 to 1.16 & 15 & 0.59 & 0.35 to 0.98 \\
\hline FW & 4 & 0.65 & 0.18 to 1.65 & $<5$ & - & - \\
\hline $\mathrm{HD}$ & 131 & 1.42 & 1.20 to 1.68 & 10 & 1.09 & 0.63 to 1.89 \\
\hline LW & 131 & 1.18 & 0.98 to 1.40 & 15 & 1.11 & 0.65 to 1.88 \\
\hline MW & 10 & 0.92 & 0.44 to 1.70 & 10 & 1.44 & 0.72 to 2.88 \\
\hline MN & 2 & 1.75 & 0.21 to 6.34 & $<5$ & - & - \\
\hline PA & 8 & 1.29 & 0.56 to 2.54 & $<5$ & - & - \\
\hline PL & 0 & - & 0.00 to 21.7 & 5 & 2.90 & 1.20 to 6.98 \\
\hline $\mathrm{PI}$ & 72 & 1.47 & 1.15 to 1.85 & 10 & 1.21 & 0.63 to 2.34 \\
\hline $\mathrm{RP}$ & 101 & 1.01 & 0.82 to 1.22 & $<5$ & - & - \\
\hline SW & 205 & 1.27 & 1.10 to 1.46 & 185 & 1.06 & 0.91 to 1.23 \\
\hline TH & 458 & 0.81 & 0.73 to 0.90 & 125 & 0.91 & 0.75 to 1.11 \\
\hline TW & 22 & 1.65 & 1.03 to 2.50 & & & \\
\hline WA & 268 & 1.30 & 1.15 to 1.47 & & & \\
\hline WE & 4 & 1.08 & 0.30 to 2.77 & $<5$ & - & - \\
\hline
\end{tabular}

*Model adjusted for age, sex, region and level of education.

Bold indicates statistically significant increased risk. Italics indicate statistically significant decreased risk.

AM, administrators and managers; AW, agriculture workers; CanCHEC, Canadian Census Health and Environment Cohort; CH, chemical workers; CS, chimney-sweeps; CW, construction workers; DV, drivers; EW, electrical workers; FB, food and beverage workers; FF, fire fighters; FP, food-processing workers; FW, forestry workers; HD, hairdressers; LW, laundry workers; MN, miners; MW, metal workers; NOCCA; Nordic Occupational Cancer study; PA, painters; PI, printers; PL, plumbers; RP, rubber and plastics workers; SIR, standardised incidence ratio; SW, sales workers; TH, teachers; TW, tobacco workers; WA, waiters; WE, welders.

participants ${ }^{24}$ and a nationwide case-control study from New Zealand ${ }^{25}$ did not observed the clear increase in risk in these studies. The New Zealand study had observed some evidence for increased risks of bladder cancer among female drivers. ${ }^{25}$ A meta-analysis ${ }^{26}$ suggested that the occupational risk of bladder cancer among drivers has been reduced in recent years, which may be reflected in our findings for male drivers.

This comparative study also observed evidence of an association between the risk of bladder cancer and employment as a plumber. The excess risk in the CanCHEC cohort was observed among a small number of female plumbers in the study. Existing evidence has been similarly inconclusive. Studies in the USA have reported increased risks of bladder cancer in male plumbers ${ }^{24} 27$ but this association was not observed among plumbers in an Italian case-control study. ${ }^{28}$ Plumbers are exposed to many hazardous materials such as lead, welding fumes, tars and asbestos, which makes it difficult to identify the putative agents. ${ }^{24} 27$

Painters are commonly exposed to aromatic amines such as benzidine, 4-aminobiphenyl, $\beta$-naphthylamine and 4-chloro-o-toluidine and exposure to these substances has been linked to bladder cancer. ${ }^{29}$ The International Agency for Research on Cancer (IARC) classified occupational exposure as a painter as carcinogenic to humans (group 1) mainly based on observed increased risks of lung cancer and bladder cancer. Although not reaching statistical significance, painters appeared to have an increased risk of bladder cancer in our comparative study. A meta-analysis reported a smoking-adjusted significant increased risk of bladder cancer among painters, which was consistently observed across 36 observational studies regardless of study design, sex and study location. ${ }^{30}$ 
Though the specific agents attributable for the risk of bladder cancer in painters have not been clearly identified, exposure to metal coatings, wood varnishes or stains that contain solvents, fillers and pigments are suggested risk factors. ${ }^{30}$

Miners appeared to be at increased risk of bladder cancer in our comparative study. This association was previously reported in studies from both Europe ${ }^{82021}$ and Canada. ${ }^{81}$ Miners have known occupational exposures to chemical compounds such as $\mathrm{PAH}$, which have been suggested as a strong risk factor in the aetiology of bladder cancer. ${ }^{32}$ This increased risk could be due to a number of exposures in the mining setting. Miners can be exposed to relatively high levels of diesel exhaust, primarily among underground transportation workers, where excess risks of bladder cancer have previously been observed. ${ }^{31}$

Increased risk was observed among female dry cleaners in our comparative study, although risk estimates were not statistically significant. A recent meta-analysis of dry cleaning workers reported a significantly elevated risk of bladder cancer, and the excess risk did not appear to be confounded by smoking. ${ }^{33}$ A case-control study from the USA also observed a similar increased risk of bladder cancer among dry cleaners, but this study was limited to non-white men. ${ }^{9}$ In the NOCCA study, it was not possible to separate dry cleaners from other laundry workers and hence we used dry cleaners as a comparison group to launderers. Use of tetrachloroethylene was by far the dominant solvent among Nordic dry cleaners. Launderers can be exposed to tetrachloroethylene, which is a potential bladder carcinogen according to IARC (group 2A). ${ }^{33}$

Our study observed significantly elevated risk of bladder cancer associated with welding only among men in the CanCHEC cohort. An IARC working group had previously explored this association, and it was deemed limited and inconclusive. ${ }^{34}$ Since the 1990 IARC evaluation, many studies have reported elevated risks of bladder cancer associated with welding. Several of these studies have, however, included small sample sizes or small numbers of cases. A hospital-based case-control study in France reported a sevenfold increased risk of bladder cancer in male welders compared with controls. ${ }^{32}$ However, the association observed was not statistically significant. Excess risk of bladder cancer was also reported in the German-based study among welders who had worked for at least 6 months in this occupation at the time of first follow-up (standardised mortality ratio 3.04, 95\% CI 1.14 to 8.10 ), but the risk estimate was observed to be non-statistically significant with extended follow-up. ${ }^{35}$ While the strongest evidence of cancer risk in welders is lung cancer, the study suggests that occupational associations with bladder cancer are most probably due to exposures specific to welding fumes that may contribute to the risk of bladder cancer. ${ }^{12}$

Reduced risks of bladder cancer were associated with employment as a teacher and agricultural worker. These protective effects have been reported in a previous meta-analysis. ${ }^{36}$ Consistently, lower risk of bladder cancer was observed among agricultural workers in Spanish studies. ${ }^{2021}$ Low prevalence of smoking, high physical demand of exercise in farming occupations, dietary factors such as high intake of fresh food and vegetables and residence in areas with little air pollution might account for the reduced risk of bladder cancer among farmers. ${ }^{21}{ }^{36} \mathrm{In}$ contrast, a 2009 study from the USA reported long-term employment as an agricultural worker was associated with increased risk of bladder cancer. ${ }^{37}$ The study suggested that long-term exposure to carcinogenic agents such as pesticides, solvents and other inorganic dusts could contribute to the increased risk of bladder cancer among agricultural workers. ${ }^{37}$

Smoking is the strongest known risk factor of bladder cancer and an important potential confounder in the studies of occupational bladder cancer. ${ }^{38}$ The CanCHEC study allowed for adjustment for education, which aimed to indirectly control for occupational difference in smoking. Smoking has been shown to be strongly correlated with education levels and has been suggested as an appropriate proxy in model adjustment in the absence of individual-level smoking data. ${ }^{39}$ The study also observed higher risk of smoking associated with lower education level. In our NOCCA-CanCHEC comparative study, those occupational groups at highest risk of bladder cancer were also commonly identified as at risk of lung cancer. Correlation of bladder and lung cancer in both the NOCCA and the CanCHEC studies in men suggests that smoking or some other shared risk factor(s) may be responsible for excess risks observed by occupations (figure 2). However, we also observed some outliers in the graph including dry cleaners, hairdressers and welders, which may indicate some occupation-specific risk factors for these groups.

Previous attempts to disentangle the effects of occupational exposures from smoking have indicated that smoking does not account for all of the excess risk of bladder cancer. ${ }^{12}{ }^{40}$ Although hairdressers have a higher prevalence of smoking compared with other workers and the general population, ${ }^{16}$ Takkouche et al observed no difference in effect among this group with adjustment to smoking. ${ }^{15}$ Adjustment for smoking also appeared to have little to no effect on risk estimates for painters,${ }^{30}$ hairdressers, ${ }^{14}$ printers, transportation workers, ${ }^{20}$ machine operators $^{21}$ and plumbers. ${ }^{27}$ This supports the hypothesis that at least some occupational variation in bladder cancer risk can be explained by occupational difference in smoking. ${ }^{12}$ However, we cannot rule out the possibility of residual confounding in our study.

This comparison of two large cohort studies conducted in different geographic regions aimed to describe variation in bladder cancer risk across occupations was unable to identify specific occupational patterns in risk of bladder cancer except for sales workers. Furthermore, Nordic peoples have long occupational history as compared with the Canadians. If we were unable to identify the specific risk of bladder cancer that would be similarly high in both 
geographic regions, one of the reasons may be that some of the risk estimates in one or both regions may be diluted towards unity. If only a small fraction of the workers are exposed, the effect may not be seen in the risk estimate of the entire occupational category. Additionally, occupation at one point in time does not necessarily correspond to lifelong occupational history. Some of the persons in non-exposed categories may actually have had exposure to bladder carcinogens in other jobs. This would result in misclassification and an attenuation of risk estimates.

Strengths of this study include the large cohort sizes, long duration of follow-up and large number of cases observed, although the NOCCA cohort was stronger in all of these aspects. However, the numbers of cases in some of the smaller occupational categories were too few to precisely measure associations. The use of existing registries captured virtually all incident cancer cases. The linkage between the census, mortality and immigration, and cancer incidence data were based on unique personal identity codes used in registries in all Nordic countries ${ }^{12}$ and through deterministic and probabilistic methods in CanCHEC that ensures a high probability of ascertaining of relevant events. The use of existing data sources including the censuses and mortality and mobility records was an efficient approach for surveillance of large populations.

\section{CONCLUSION}

We observed different occupational patterns in risk of bladder cancer in Nordic countries and Canada. This comparative study identified consistency in risk only among sales workers. Risks of bladder cancer varied across occupational categories. Although exposure to carcinogens at work may contribute this variation, however, the present comparison of bladder cancer pattern in the Nordic countries and in Canada did not identify clues to the disease aetiology. The study illustrates that the possible effect of specific occupational exposure may be difficult to unravel in the datasets following people with work experiences from different time periods and categories into broad occupational groups.

\footnotetext{
Author affiliations

${ }^{1}$ Department of Epidemiology, Faculty of Social Sciences, University of Tampere, Tampere, Finland

${ }^{2}$ Occupational Cancer Research Centre, Toronto, Canada

${ }^{3}$ Dalla Lana School of Public Health, University of Toronto, Toronto, Ontario, Canada ${ }^{4}$ CAREX Canada, Faculty of Health Sciences, Simon Fraser University, Burnaby, Canada

${ }^{5}$ Department of Research, Cancer Registry of Norway, Institute of Population-Based Cancer Research, 0slo, Norway

${ }^{6}$ Department of Community Medicine, Faculty of Health Sciences, University of

Troms $\emptyset$, The Arctic University of Norway, Troms $\emptyset$, Norway

${ }^{7}$ Genetic Epidemiology Group, Folkhälsan Research Center, Helsinki, Finland

${ }^{8}$ Department of Medical Epidemiology and Biostatistics, Karolinska Institutet,

Stockholm, Sweden

${ }^{9}$ Center for Epidemiology and Screening, Institute of Public Health, University of

Copenhagen, Copenhagen, Denmark

${ }^{10}$ Icelandic Cancer Registry, Reykjavik, Iceland

${ }^{11}$ Faculty of Medicine, University of Iceland, Reykjavik, Iceland

${ }^{12}$ School of Occupational and Public Health, Ryerson University, Toronto, Canada
}

${ }^{13}$ Health Analysis Division, Statistics Canada, Ottawa, Ontario, Canada

${ }^{14}$ Department of Sociology and Economics, University of New Brunswick Fredericton Campus, New Brunswick, Canada

${ }^{15}$ Finnish Cancer Registry, Institute for Statistical and Epidemiological Cancer Research, Helsinki, Finland

Contributors $\mathrm{KH}, \mathrm{JM}, \mathrm{PAD}$ and EP designed, analysed and prepared the manuscript. KH, JIM, EW, KK, EL, PS, LT and EP are responsible for NOCCA and JM and PAD are responsible for CanCHEC cohorts. KH, JM, PAD, JIM, EW, KK, EL, PS, LT, MAH, MT, PAP and EP revised, reviewed, provided critical feedbacks and approved the manuscript for final submission.

Funding This work was supported by funding from the Nordic Cancer Union. The CanCHEC analysis was funded by a grant from the Ontario Workplace Safety and Insurance Board Research Advisory Council (\#11024) and supported by the Ontario Ministry of Labour and the Canadian Cancer Society Research Institute. Linkage of the 1991 Canadian Census to the Canadian Cancer Registry was funded by the Canadian Institute for Health Information, Health Canada and Statistics Canada. This research was supported by funds to the Canadian Research Data Centre Network from the Social Science and Humanities Research Council, the Canadian Institute for Health Research, the Canadian Foundation for Innovation and Statistics Canada. Although the research and analysis are based on data from Statistics Canada, the opinions expressed do not represent the views of Statistics Canada or the Canadian Research Data Centre Network.

Competing interests None declared.

Ethics approval Prior approval was obtained and no additional approval was needed for this specific study.

Provenance and peer review Not commissioned; externally peer reviewed. Data sharing statement No additional data are available.

Open Access This is an Open Access article distributed in accordance with the Creative Commons Attribution Non Commercial (CC BY-NC 4.0) license, which permits others to distribute, remix, adapt, build upon this work non-commercially, and license their derivative works on different terms, provided the original work is properly cited and the use is non-commercial. See: http://creativecommons.org/ licenses/by-nc/4.0/

(c) Article author(s) (or their employer(s) unless otherwise stated in the text of the article) 2017. All rights reserved. No commercial use is permitted unless otherwise expressly granted.

\section{REFERENCES}

1. Vineis $P$, Simonato L. Proportion of lung and bladder cancers in males resulting from occupation: a systematic approach. Arch Environ Health 1991;46:6-15.

2. Dreyer L, Winther JF, Pukkala E, et al. Avoidable cancers in the Nordic countries. Tobacco smoking. APMIS Supp/ 1997;76:9-47.

3. International Agency for research on Cancer. GLOBOCAN: Estimated Cancer Incidence, Mortality and Prevalence worldwide in 2012. http://globocan.iarc.fr/Pages/fact_sheets_population.aspx (accessed 20 Dec 2015)

4. Association of the Nordic Cancer Registries. NORDCAN: cancer incidence and mortality in the nordic countries, Version 7.1. 2015 http://www.ancr.nu. (accessed 18 Aug 2015).

5. Canadian Cancer statistics 2015. Special topic: Predictions of the future burden of cancer in Canada. https://www.cancer.ca/ /media/ cancer.ca/CW/cancer\%20information/cancer\%20101/Canadian\% 20cancer\%20statistics/Canadian-Cancer-Statistics-2015-EN.pdf. (accessed 28 Jan 2016).

6. Cogliano VJ, Baan R, Straif K, et al. Preventable exposures associated with human cancers. J Natl Cancer Inst 2011;103:1827-39.

7. Silverman DT, Hoover RN, Mason TJ, et al. Motor exhaust-related occupations and bladder cancer. Cancer Res 1986;46(4 Pt 2):2113-6.

8. Reulen RC, Kellen E, Buntinx F, et al. A meta-analysis on the association between bladder cancer and occupation. Scand J Uro Nephrol Suppl 2008;218:64-78.

9. Silverman DT, Levin LI, Hoover RN. Occupational risks of bladder cancer in the United States: II Nonwhite men. J Nat/ Cancer Inst 1989;81:1480-3.

10. Ji J, Granström C, Hemminki K. Occupation and bladder cancer: a cohort study in Sweden. Br J Cancer 2005;92:1276-8. 
11. Engholm G, Hakulinen T, Gislum M, et al. Trends in the survival of patients diagnosed with kidney or urinary bladder cancer in the Nordic countries 1964-2003 followed up to the end of 2006. Acta Oncol 2010;49:655-64.

12. Pukkala E, Martinsen JI, Lynge E, et al. Occupation and cancer follow-up of 15 million people in five Nordic countries. Acta Oncol 2009;48:646-790.

13. Peters PA, Tjepkema M, Wilkins R, et al. Data resource profile: 1991 Canadian Census Cohort. Int J Epidemiol 2013;42:1319-26.

14. Harling M, Schablon A, Schedlbauer G, et al. Bladder cancer among hairdressers: a meta-analysis. Occup Environ Med 2010;67:351-8.

15. Takkouche B, Regueira-Méndez C, Montes-Martínez A. Risk of cancer among hairdressers and related workers: a meta-analysis. Int J Epidemiol 2009;38:1512-31.

16. IARC monographs on the evaluation of carcinogenic risks to humans. occupational exposure of hairdressers and barbers and personal use of hair colorants; some hair dyes; cosmetic colorants, industrial dye stuffs and aromatic amines. IARC Monogr Eval Carcinog Risk Hum 1993;57:1-437 http://monographs.iarc.fr/ENG/Monographs/vol57/ mono57.pdf.

17. Ferrís J, Garcia J, Berbel O, et al. Constitutional and occupational risk factors associated with bladder cancer. Actas Urol Esp 2013;37:513-22.

18. Pukkala E, Nokso-Koivisto P, Roponen P. Changing cancer risk pattern among Finnish hairdressers. Int Arch Occup Environ Health 1992;64:39-42.

19. Bolt HM, Golka K. The debate on carcinogenicity of permanent hair dyes: new insights. Crit Rev Toxicol 2007;37:521-36.

20. Kogevinas M, 't Mannetje A, Cordier S, et al. Occupation and bladder cancer among men in Western Europe. Cancer Causes Control 2003:14:907-14.

21. Samanic CM, Kogevinas M, Silverman DT, et al. Occupation and bladder cancer in a hospital-based case-control study in Spain. Occup Environ Med 2008;65:347-53. 2008.

22. IARC monographs on the evaluation of carcinogenic risks to humans. printing processes and printing inks, carbon black and some nitro compounds. IARC Monogr Eval Carcinog Risk Hum 1996;65:1-115 http://monographs.iarc.fr/ENG/Monographs/vol65/ mono65-5.pdf.

23. 't Mannetje A, Pearce N. Bladder cancer risk in sales workers: artefact or cause for concern? Am J Ind Med 2006;49:175-86.

24. Colt JS, Karagas MR, Schwenn M, et al. Occupation and bladder cancer in a population-based case-control study in Northern New England. Occup Environ Med 2011;68:239-49.

25. Dryson E, 't Mannetje A, Walls $\mathrm{C}$, et al. Case-control study of high risk occupations for bladder cancer in New Zealand. Int $J$ Cancer 2008;122:1340-6.
26. Manju L, George PS, Mathew A. Urinary bladder cancer risk among motor vehicle drivers: a meta-analysis of the evidence, 1977-2008. Asian Pac J Cancer Prev 2009;10:287-94.

27. Zheng T, Cantor KP, Zhang Y, et al. Occupation and bladder cancer: a population-based, case-control study in lowa. J Occup Environ Med 2002;44:685-91.

28. Puntoni R, Merlo F, Borsa L, et al. A historical cohort mortality study among shipyard workers in Genoa, Italy. Am J Ind Med 2001;40:363-70.

29. Bachand A, Mundt KA, Mundt DJ, et al. Meta-analyses of occupational exposure as a painter and lung and bladder cancer morbidity and mortality 1950-2008. Crit Rev Toxicol 2010;40:101-25.

30. Guha N, Steenland NK, Merletti F, et al. Bladder cancer risk in painters: a meta-analysis. Occup Environ Med 2010;67:568-73.

31. Gaertner RR, Trpeski L, Johnson KC.A case-control study of occupational risk factors for bladder cancer in Canada. Cancer Causes Control 2004;15:1007-19.

32. Cordier S, Clavel J, Limasset JC, et al. Occupational risks of bladder cancer in France: a multicentre case-control study. Int J Epidemiol 1993;22:403-11.

33. Vlaanderen J, Straif K, Ruder A, et al. Tetrachloroethylene exposure and bladder cancer risk: a meta-analysis of dry-cleaning-worker studies. Environ Health Perspect 2014;122:661-6.

34. IARC monographs on the evaluation of carcinogenic risks to humans. Chromium, Nickel and welding. IARC Monogr Eval Carcinog Risk Hum 1990;49:1-687 http://monographs.iarc.fr/ENG/Monographs/ vol49/mono49.pdf

35. Becker N. Cancer mortality among arc welders exposed to fumes containing chromium and nickel. Results of a third follow-up: 19891995. J Occup Environ Med 1999;41:294-303.

36. Blair A, Zahm SH, Pearce NE, et al. Clues to cancer etiology from studies of farmers. Scand J Work Environ Health 1992;18:209-15.

37. Cassidy A, Wang W, Wu X, et al. Risk of urinary bladder cancer: a case-control analysis of industry and occupation. BMC Cancer 2009;9:443

38. International Agency for Research on Cancer. IARC monographs on the evaluation of carcinogenic risk to humans. Agents classified by the IARC monographs, Volumes 1 to $117 \mathrm{http}: / /$ monographs.iarc.fr/ ENG/Classification/index.php.

39. Winkleby MA, Jatulis DE, Frank E, et al. Socioeconomic status and health: how education, income, and occupation contribute to risk factors for cardiovascular disease. Am J Public Health 1992;82:816-20.

40. Shiels MS, Gibson T, Sampson J, et al. Cigarette smoking prior to first cancer and risk of second smoking-associated cancers among survivors of bladder, kidney, head and neck, and stage I lung cancers. J Clin Oncol 2014;32:3989-95. 